\title{
Structural, Thermal, and Release Properties of Hybrid Materials Based on Layered Zinc Hydroxide and Caffeic Acid
}

\author{
Christhy V. Ruiz ${ }^{1,2,3}$, María E. Becerra ${ }^{1,2,3,4,5}$ and Oscar Giraldo ${ }^{1,2,4, *(1)}$ \\ 1 Laboratorio de Materiales Nanoestructurados y Funcionales, Facultad de Ciencias Exactas y Naturales, \\ Universidad Nacional de Colombia- Sede Manizales, Kilometro 9 vía al aeropuerto, La Nubia, \\ 170003 Manizales, Colombia; cvruizma@unal.edu.co (C.V.R.); mebecerrah@unal.edu.co (M.E.B.) \\ 2 Grupo de Investigación en Procesos Químicos, Catalíticos y Biotecnológicos, Universidad Nacional de \\ Colombia-Sede Manizales, Kilometro 9 vía al aeropuerto, La Nubia, 170003 Manizales, Colombia \\ 3 Departamento de Ingeniería Química, Facultad de Ingeniería y Arquitectura, Universidad Nacional de \\ Colombia-Sede Manizales, Kilometro 9 vía al aeropuerto, La Nubia, 170003 Manizales, Colombia \\ 4 Departamento de Física y Química, Facultad de Ciencias Exactas y Naturales, Universidad Nacional de \\ Colombia-Sede Manizales, Kilometro 9 vía al aeropuerto, La Nubia, 170003 Manizales, Colombia \\ 5 Departamento de Química, Universidad de Caldas, Calle 65 No. 26-10, 17001 Manizales, Colombia \\ * Correspondence: ohgiraldoo@unal.edu.co
}

Received: 10 December 2019; Accepted: 14 January 2020; Published: 17 January 2020

\begin{abstract}
Caffeic acid (CA) molecules were immobilized in a layered inorganic host matrix based on zinc hydroxide structures with different starting interlayer anions, nitrate, and acetate. The chemical composition, structure, thermal stability, morphology, and surface of the host matrices and hybrid compounds were analyzed by X-ray diffraction (XRD), themogravimetric/differencial thermal analysis (TG/DTA), Fourier transform infrarred spectroscopy (FT-IR), scanning electron microscopy (SEM), and X-ray photoelectron spectroscopy (XPS). Additionally, the surface charge of the materials was investigated using zeta potential at $\mathrm{pH} \sim 7$. The results show an influence of the surface charge on the chemical, interaction, and structure of the resulting hybrid materials as a function of the starting layered structures. An expansion of the basal spacing to $10.20 \AA$ for zinc hydroxide nitrate (ZHN), and a shrinkage to $10.37 \AA$ A for zinc hydroxide acetate (ZHA). These results suggest that the CA lies with a tilt angle in the interlayer region of the inorganic host matrix. The immobilization of $C A$ is favored in $\mathrm{ZHN}$, with respect to $\mathrm{ZHA}$, because a single-layered phase was identified. A higher thermal stability at $65^{\circ} \mathrm{C}$ was observed for ZHN-CA than for ZHA-CA. The evaluation of the release behavior showed a higher percentage of CA released from ZHN than ZHA, and the release mechanism was described by the Elovich model. The hybrid materials show potential characteristics for use as bioactive delivery systems.
\end{abstract}

Keywords: layered zinc hydroxide; caffeic acid; hybrid material; release systems; immobilization

\section{Introduction}

Layered inorganic materials, such as layered double hydroxides (LDH) and zinc hydroxy salts (ZHS), are characterized by retaining different chemical species compatible in the interlayer region due to the charge of their layers, thereby achieving the charge balance of the layered structure. This possibility enables the creation of a wide variety of hybrid materials with new applications and functionalities [1]. The differences between LDH and ZHS in terms of the layer structure and bonding confer different physicochemical and interfacial properties to the materials. The materials of the LDH family consist of octahedral layers formed by the partial substitution of divalent metal ions $\left(\mathrm{M}^{2+}\right)$ by 
trivalent metal ions $\left(\mathrm{M}^{3+}\right)$, with the interlayer anion balancing the positive charge. In contrast, in the ZHS, one-quarter of the octahedral sites of $\mathrm{Zn}^{2+}$ atoms are empty. Instead, $\mathrm{Zn}^{2+}$ ions are placed in tetrahedral sites at the bottom and top of each empty octahedron [2], with three hydroxyl groups forming the base of the tetrahedron, and, on the apex, a water molecule is coordinated. With regard to layered double hydroxides (LDH), a wide range of molecules such as complex ions, vitamins, organic acids, genes, and drugs, amongst others, were extensively investigated [3-7]. However, in terms of ZHS, there is still much to be explored about immobilization studies of functional molecules, such as antioxidants, dyes, and drugs [8,9].

The immobilization process, using zinc hydroxide salts (ZHS) such as zinc hydroxide nitrate $(\mathrm{ZHN})$ and zinc hydroxide acetate (ZHA), takes advantage of the structural characteristics of these layered host materials and their possibility to form covalent binding with different chemical species. The zinc hydroxide salts consist of cationic zinc hydroxy layers and associated anions. The positive charge of the layer can be compensated for with free nitrate ions for ZHN and acetate anions for ZHA in the interlayer region $[10,11]$. The new materials using $Z H N$ as a host matrix exhibited improved characteristics as in the case of ciprofloxacin intercalated into ZHN, where the intercalated compound showed stronger anti-cancer effects against A549 cancer cells compared to the pure ciprofloxacin molecule [12], or the nanocomposite developed by the intercalation of hippuric acid into $\mathrm{ZHN}$, which presented better anti-microbial properties against drug-resistant bacteria compared to free hippuric acid [13].

Bioactive molecules, of natural origin, attracted considerable attention in the last few years due to their valuable biological and physiological properties [14]. The exchange anion capability, offered by ZHN and ZHA, also allows the incorporation of these types of biomolecules. One such bioactive molecule is caffeic acid (CA), which possesses antioxidant, anticancer, anti-inflammatory, and antiviral properties [15-17]. The anion exchange of caffeic acid in $\mathrm{Mg}-\mathrm{Al} \mathrm{LDH}$ was evaluated by Ito et al.; however, their study was only conducted in order to synthesize a CA-LDH intercalated compound [18]. On the other hand, Choy et al. encapsulated caffeic acid in zinc hydroxide nitrate to evaluate the ultraviolet UVA1 screening ability of the nanohybrid material. However, the thermal and surface characterization was not studied in detail [19].

Therefore, this study aims to incorporate caffeic acid into ZHN and ZHA inorganic host matrices, to determine the effect on the structural, thermal, and surface properties of the hybrid materials obtained from different layered starting materials for the immobilization process of the active molecule, as well as to evaluate the release behavior of the hybrid material for practical cosmetic and pharmaceutical applications.

\section{Materials and Methods}

Materials and Synthesis of Samples

\subsubsection{Synthesis of Layered Zinc Hydroxide}

Zinc hydroxide nitrate (ZHN) and zinc hydroxide acetate (ZHA) were synthesized using the method reported in previous work [20,21]. For each compound, aqueous solutions with $23.88 \mathrm{~g}$ of $\mathrm{Zn}\left(\mathrm{NO}_{3}\right)_{2} \cdot 4 \mathrm{H}_{2} \mathrm{O}$ (Merck $98.9 \%$, St. Louis, MO, USA) and $16.24 \mathrm{~g}$ of $\mathrm{Zn}\left(\mathrm{CH}_{3} \mathrm{CO}_{2}\right)_{2}$ (Merck 99.9\%, St. Louis, MO, USA) were prepared in $60 \mathrm{~mL}$ of deionized water. Thereafter, the solutions were mixed in different suspensions, with $7.39 \mathrm{~g} / 60 \mathrm{~mL}$ of zinc oxide (ZnO) (Sigma Aldrich $99 \%-100 \%$, St. Louis, $\mathrm{MO}$, USA) with constant stirring for $24 \mathrm{~h}$. The white slurries were centrifuged, washed three times with deionized water, and dried at room temperature.

\subsubsection{Synthesis of Hybrid Material}

The immobilization of caffeic acid (CA) (Alfa Aesar, 3,4-dihydroxycinnamic acid, predominantly trans, 99\%, Ward Hill, MA, USA) was conducted by the dispersion of $5.00 \mathrm{~g}$ of ZHN and ZHA, independently, in a suspension of $50.0 \mathrm{~mL}$ of deionized water with $1.82 \mathrm{~g}$ of CA. The resultant 
suspensions were stirred at room temperature for $24 \mathrm{~h}$. The solid product was recovered by centrifuge and washed three times with deionized water as described above. The product was dried for $72 \mathrm{~h}$ at room temperature.

\subsubsection{Characterization of Hybrid Materials}

The characterization of the materials was done by elemental analysis, X-ray diffraction, thermal analysis, Fourier transform-infrared spectroscopy, scanning electron microscopy, and X-ray photoelectron spectroscopy. The chemical composition was estimated from a quantitative combustion technique of carbon, hydrogen, and nitrogen on a Leco TruSpec Micro CHNSO elemental analyzer (St. Joseph, MI, USA), and atomic absorption spectroscopy to determine zinc content on a Thermo Scientific iCE 3000 AA spectrometer (Waltham, MA, USA). The surface charge of the materials was measured using a Malvern Zetasizer Nano ZS instrument (Alcobendas, Madrid, Spain) in 0.1 mol/L $\mathrm{NaOH}$. The XRD patterns were conducted with a Rigaku Miniflex II Diffractometer (Woodlands, TX, USA) with CuK $\alpha$ radiation (1.541 $\AA$ ) at $30 \mathrm{kV}$ and $15 \mathrm{~mA}$. Thermal analysis was carried out using TGA Q500 (New Castle, DE, USA) from $25{ }^{\circ} \mathrm{C}$ to $700{ }^{\circ} \mathrm{C}$ at a heating rate of $10{ }^{\circ} \mathrm{C} \cdot \mathrm{min}^{-1}$ in a nitrogen atmosphere. The FTIR spectra were recorded at room temperature for powder samples with a Mid-Infrared FT-IR Nicolet iS5 Thermo Fisher Spectrometer (Waltham, MA, USA) in the range of $4000 \mathrm{~cm}^{-1}$ to $400 \mathrm{~cm}^{-1}$, with a resolution of $4.0 \mathrm{~cm}^{-1}$ using pellets prepared with $\mathrm{KBr}$. Scanning electron microscope images were collected on a JEOL JSM-6490LV equipment (North Billerica, MA, USA) with an acceleration voltage of $20 \mathrm{kV}$. X-ray photoelectron spectroscopy was performed on a PHI 5000 Versa Probe II Scanning XPS Microprobe (Chanhassen, MN, USA) with monochromatic $\mathrm{Al} \mathrm{K} \alpha$ radiation. The spectra were obtained at a takeoff angle of $45^{\circ}$ to the sample normal using a spot diameter of $100 \mu \mathrm{m}$. In all samples, the binding energy was referenced using the $\mathrm{C} 1 \mathrm{~s}$ peak at $284.5 \mathrm{eV}$ [22]. The high-resolution spectra were used for elemental quantification of the compounds using Multipak data processing software [23]. The schematic representation of the intercalation process in this work was made with CrystalMaker software (Begbroke, OX5, UK) [24].

\subsubsection{Controlled Release Studies}

The experiments were performed using a buffer solution ( $\mathrm{pH} 7.1)$ by dissolving $\mathrm{NaH}_{2} \mathrm{PO}_{4}(0.0534 \mathrm{~g})$ and $\mathrm{Na}_{2} \mathrm{HPO}_{4}(0.2195 \mathrm{~g})$ in deionized water to make $1000 \mathrm{~mL}$ of a solution. The hybrid compounds $(0.050 \mathrm{~g})$ were added to $1000 \mathrm{~mL}$ of the buffer solution with continuous stirring. Aliquots of $5.0 \mathrm{~mL}$ were collected from the reaction at regular intervals. The concentration in each one of the aliquots was measured in triplicate by UV spectroscopy using a lambda UV-visible light spectrophotometer at $19.0 \pm$ $1{ }^{\circ} \mathrm{C}$. The maximum absorption wavelength in all solutions of the hybrid materials, in the release study, was $265 \mathrm{~nm}$. Initially, the calibration curve was generated to calculate the amount of intercalated CA using eight aqueous solutions with concentrations ranging from 0.0 to $50.0 \mathrm{mg} / \mathrm{L}$ of phosphate buffer solution (pH 7.1) with $50.0 \mathrm{mg} / \mathrm{L}$ of CA concentration. The least-square method was employed to fit the equation of the calibration curve of the $y=a x+b$ form, resulting in $a=4.123 \times 10^{-2}$, and $b=-18.51 \times 10^{-3}$ with $R^{2}$ $=0.999$, where $x$ is the absorbance and $y$ is the CA solution concentration, expressed in $\mathrm{mg} / \mathrm{L}$.

\section{Results and Discussion}

\subsection{Elemental Analysis}

The elemental analyses of the hybrid materials based on layered zinc hydroxide salts and caffeic acid, as well as those of the inorganic host matrices, are presented in Table 1. The calculated formulas were estimated from the stoichiometry comparison of the experimental data and theoretical values of the ideal formula $\mathrm{Zn}_{5}(\mathrm{OH})_{8}(\mathrm{CA})_{2} \cdot 2 \mathrm{H}_{2} \mathrm{O}$. The absence of the starting interlayer anions of the host matrices (nitrate and acetate anions), taking into account the calculated formula from the chemical composition, indicates that the guest anion (caffeate) was immobilized into the layered structure to form the hybrid materials. For the hybrid material from zinc hydroxide nitrate, a content of $43.6 \%$ of caffeic 
acid was determined, whereas, for zinc hydroxide acetate, the content was $43.1 \%$. These estimated values are close to that represented by the theoretical formula. The difference in the composition of the hybrid materials as a function of the starting host matrices, zinc hydroxide nitrate (ZHN) and zinc hydroxide acetate (ZHA), given the variation of the content of water, hydroxyl groups, and caffeate anions, can be related to the difference in the interaction mode between the guest anion and the layers after displacement of the starting anions, which led to a modification of structure for the resulting hybrid material.

Table 1. Chemical composition and calculated formula of the hybrid materials.

\begin{tabular}{|c|c|c|c|c|c|}
\hline \multirow{2}{*}{$\begin{array}{l}\text { Hybrid } \\
\text { Material }\end{array}$} & \multirow[t]{2}{*}{ Calculated Formula } & \multicolumn{4}{|c|}{$\begin{array}{c}\text { Elemental Content Percentages Observed } \\
\text { (Calculated) (wt.\%) }\end{array}$} \\
\hline & & Zn & $\mathrm{C}$ & $\mathbf{N}$ & $\mathbf{H}$ \\
\hline ZHN & $\mathrm{Zn}_{5}(\mathrm{OH})_{8}\left(\mathrm{NO}_{3}\right)_{1.6}\left(\mathrm{CO}_{3}\right)_{0.2} \cdot 1.7 \mathrm{H}_{2} \mathrm{O}$ * & $54.5(54.1)$ & $0.4(0.4)$ & $3.6(3.7)$ & $1.9(1.9)$ \\
\hline ZHA & $\mathrm{Zn}_{5}(\mathrm{OH})_{7.5}\left(\mathrm{C}_{2} \mathrm{H}_{3} \mathrm{O}_{2}\right)_{2.5} \cdot 3 \mathrm{H}_{2} \mathrm{O}$ & $50.0(49.8)$ & $9.3(9.1)$ & - & $3.2(3.2)$ \\
\hline $\mathrm{ZHN}-\mathrm{CA}$ & $\mathrm{Zn}_{5}(\mathrm{OH})_{8}\left(\mathrm{C}_{9} \mathrm{H}_{7} \mathrm{O}_{4}\right)_{2}$ & $38.7(39.8)$ & $27.5(26.3)$ & - & $2.4(2.7)$ \\
\hline ZHA-CA & $\mathrm{Zn}_{5}(\mathrm{OH})_{7.5}\left(\mathrm{C}_{9} \mathrm{H}_{7} \mathrm{O}_{4}\right)_{2.5} \cdot \mathrm{H}_{2} \mathrm{O}$ & $38.1(35.5)$ & $29.3(25.2)$ & - & $3.0(2.9)$ \\
\hline
\end{tabular}

\subsection{Interfacial Characterization}

The surface charges for the inorganic host matrices, zinc hydroxide nitrate and zinc hydroxide acetate (ZHN and ZHA), as well as the hybrid materials, were studied by measuring the zeta potential in an aqueous media of $\mathrm{pH}$ 7.0. Zeta potentials of both inorganic host matrices in the suspension were positive, with an average zeta potential given by the instrument of $24.2 \pm 1.9 \mathrm{mV}$ for $\mathrm{ZHN}$ and 38.4 $\pm 1.8 \mathrm{mV}$ for ZHA. A zeta potential distribution range from 23 to $53 \mathrm{mV}$ for ZHA and from 0.2 to $43 \mathrm{mV}$ for ZHN can be estimated in Figure 1. As it was reported by Xu et al. and Mahmoud et al., the zeta potential for $\mathrm{LDH}$ materials $(\mathrm{Mg}-\mathrm{Al} \mathrm{LDH})$ has a positive value. This value is mainly related to the structural positive charge on the electric double layer on the LDH surface [25]. In a similar case, for layered zinc hydroxide salts, the positive values can be attributed to the structural positive charge given by the $\mathrm{Zn}^{2+}$ ions placed in the octahedral and tetrahedral sites forming the layers [2]. However, the interior structural charge of the interlayer region is screened by the interlayer anions. The charge balance of the layers with the interlayer anions is not complete in the layered structure since the surface-adsorbed anions thermally vibrate and temporarily leave the electric double layer (Stern layer) toward the other electric layer called the diffusion layer, where static anions can always be found, which leads to the layered particles associated with the Stern layer having a positive charge [25].

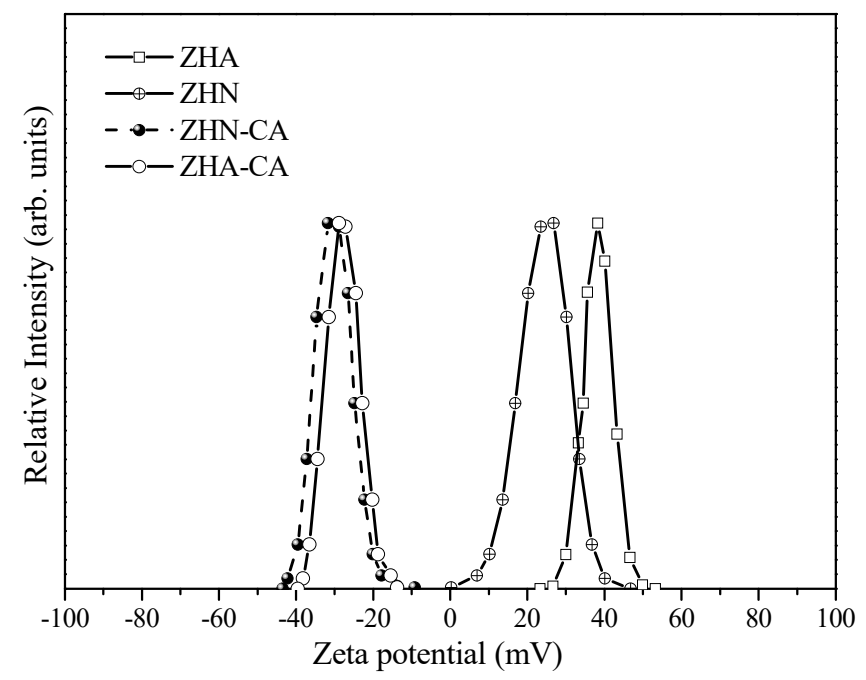

Figure 1. Zeta potential distribution of $\mathrm{ZHN}, \mathrm{ZHA}, \mathrm{ZHN}-\mathrm{CA}$, and $\mathrm{ZHA}-\mathrm{CA}$ materials. 
Therefore, the difference in the zeta potential value between the layered host matrices can be influenced by the particular characteristics of interaction between the layers and the interlayer anion in the aqueous medium. Therefore, in the case of the $\mathrm{ZHN}$, given its chemical composition from the elemental analysis, a strong adsorption of the $\mathrm{CO}_{3}{ }^{2-}$ and $\mathrm{NO}_{3}{ }^{-}$anions on the surface of the positive layers of the ZHN occurred to form the Stern layer (negative charge), which induced a lower amount of the anions present in the diffusion layer, giving rise to a smaller zeta potential value. A different response was observed for ZHA, in which a more significant zeta potential value was obtained. This response is likely associated with an electrostatic interaction through the hydrogen bonds between the water molecule located on the apex of the tetrahedral units of the layers and the oxygen atom of the acetate anion, which resulted in more acetate anions being found on the diffusion layer of the aqueous medium. Also, the difference in the composition chemical of the hydroxyl layers regarding ZHN can affect the results of the zeta potential value. The values of zeta potential are similar to those for LDH with $\mathrm{CO}_{3}{ }^{2-}$ anions reported by Xu et al. [26] and Tran et al. [27].

The values of the zeta potential of the hybrid materials based on caffeic acid and both layered zinc hydroxide host matrices were found to be negative in that ae $\mathrm{pH}$ of $\sim 7.0$. The average zeta potential for $\mathrm{ZHN}-\mathrm{CA}$ was $-29.0 \pm 0.3 \mathrm{mV}$, and ZHA-CA had a value of $-28.7 \pm 0.2 \mathrm{mV}$, with distribution zeta potentials in the range of -9.2 to $-43.5 \mathrm{mV}$ and -13.8 to $39.5 \mathrm{mV}$ for each hybrid material, respectively. The negative surface charge for the hybrid material is a fact that demonstrates the immobilization of the organic anion into the layered structure. With the $\mathrm{pH}$ in the aqueous medium, the $\mathrm{H}+$ ions of the functional groups of the caffeic acid (carboxylate group) are liberated, which leads to a more negative value of zeta potential [28]. The strong electrostatic attraction between the oxygen atom of the carboxylate group of the caffeate anion and the $\mathrm{Zn}^{2+}$ atoms of the tetrahedral units can be the cause of the zeta potential response. As a consequence of the surface charge of the starting layered host matrix, as well as the resulting chemical composition of the hybrid materials, a change in the values of zeta potential (ZHN-CA and ZHA-CA) was obtained. Based on the results of the zeta potential values, the interfacial behavior indicates suspension stability based on electrostatic interactions of the hybrid materials and the starting host matrices, which have differences owing to the chemical composition and interactions $[2,25,29,30]$.

\subsection{Powder X-Ray Diffraction (PXRD)}

The XRD patterns of the starting inorganic matrices and hybrid materials are shown in Figure 2. From now on, the inorganic-organic hybrid materials are referred to as ZHN-CA and ZHA-CA. The X-ray pattern of the inorganic matrix and hybrid materials from $\mathrm{ZHN}$ are shown in Figure 2a. For the host matrix $\mathrm{ZHN}$, the intense reflection was identified as the phase $\mathrm{Zn}_{5}(\mathrm{OH})_{8}\left(\mathrm{NO}_{3}\right)_{2} \cdot 2 \mathrm{H}_{2} \mathrm{O}$ (JCDS 72-0627) with a $d$-value of around $9.67 \AA[19,21]$. The XRD pattern for ZHN-CA revealed a shift toward lower angles of reflection, which indicates an expansion of the interlayer space of the layered structure. The increase in $d$-value from $9.67 \AA$ to $10.20 \AA$ revealed the incorporation of a larger molecule than that of the starting anions in the interlayer region. Unlike the results obtained for the ZHN inorganic matrix, the results from the hybrid material with ZHA as the starting material (Figure $2 \mathrm{~b}$ ) revealed a reduction of the interlayer space from $13.31 \AA$ [20] to $10.37 \AA$ for ZHA-CA, which is yet to be reported to our knowledge. These results are in accordance with those reported by Choy et al. [19], who recorded a $d$-spacing of $10.44 \AA$ for intercalated CA in a layered zinc hydroxide nitrate matrix (CA-ZBS). The decomposition of this ZHA-CA hybrid compound was evident, in comparison with the results obtained for hybrid material from $\mathrm{ZHN}$ inorganic host matrix, since reflections associated with $\mathrm{Zn}(\mathrm{OH})_{2}$ were observed. Furthermore, the evidence of this mixture of phases in the ZHA-CA hybrid material might justify the differences between the percentages of the elemental content observed and calculated.

Particularly, for both starting materials, the predominant arrangement, taking into account the $d$-value, is that where the organic anions (caffeate) are arranged with a tilt angle close to $70^{\circ}$ along the $z$-axis inside the interlayer space of the layered inorganic host matrix. This orientation possibly creates stronger interactions between the carboxylate group, present in the caffeic acid molecule, and the $\mathrm{Zn}^{2+}$ atoms of 
the tetrahedral units, which favor the substitution of the water molecules in the apex of tetrahedron of the layers in both cases and result in the coordination of the guest anion to the layers [31].
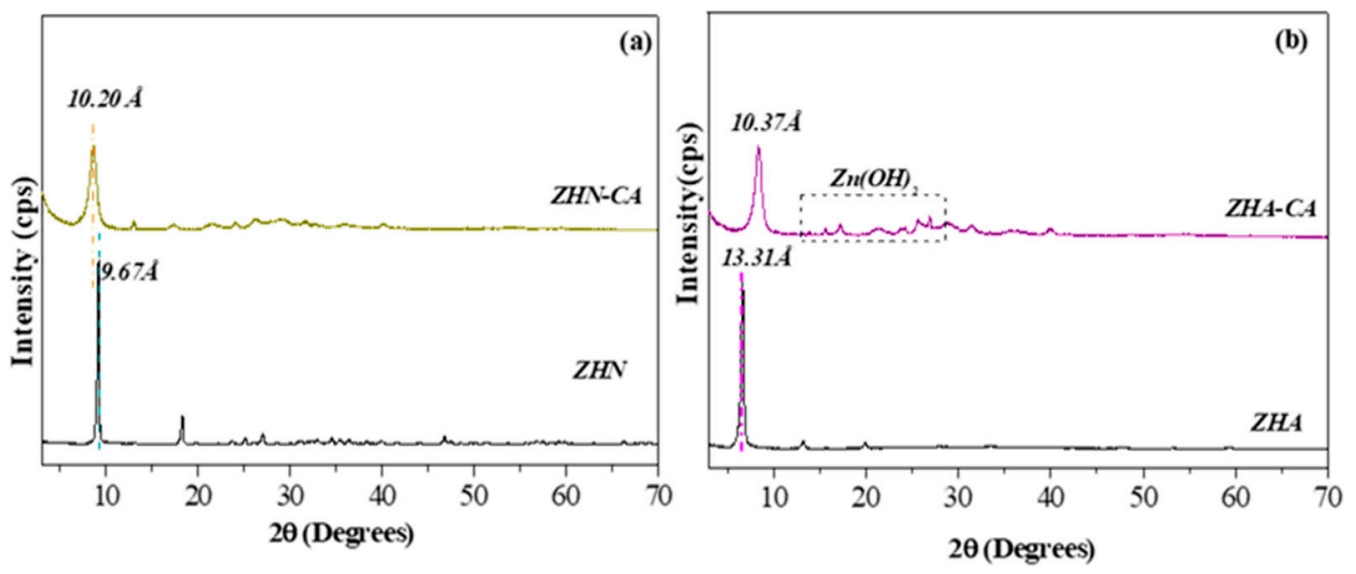

Figure 2. Powder X-Ray Diffraction patterns of (a) starting material and hybrid materials based on $\mathrm{ZHN}$ and (b) inorganic host matrix ZHA, and their intercalated compound with caffeinate anion.

The differences in the $d$-values of the resulting hybrid material, as a function of the inorganic host matrix, can be related to the initial chemical composition and surface charge of the starting layered structure. The more significant surface charge of the layers into ZHA can lead to a stronger interaction with the guest anions, giving rise to the shrinkage of the resulting layered hybrid structure, ZHA-CA, and the difference in chemical composition can affect the degradation of the layers for this hybrid material with respect to $\mathrm{ZHN}-\mathrm{CA}$.

A schematic representation of the arrangement of the caffeate anions in the interlayer space of the host matrices is illustrated in Figure 3.

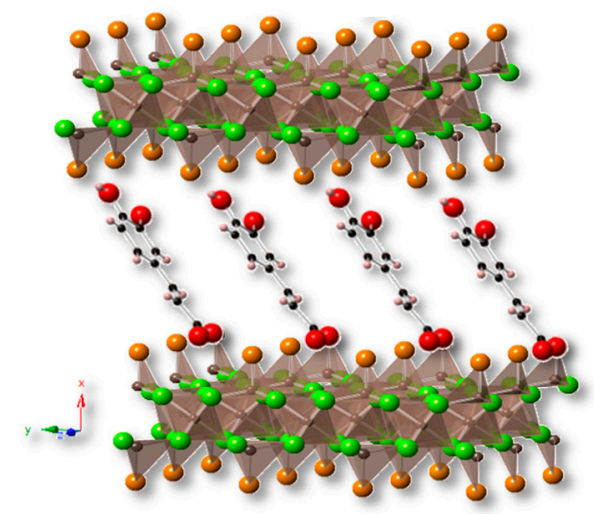

Figure 3. Representation of the caffeate anion arrangement in the interlayer space of layered structure based on ZHA and ZHN host matrix.

\subsection{Thermal Analysis (TG/DTA)}

The TG/DTA curves are shown in Figure 4a,b. The thermal decomposition of ZHN-CA occurred in three regions with a total mass loss of $34.68 \%$. The first region (I) was identified around $43.71{ }^{\circ} \mathrm{C}$ with a loss of $7.71 \%$. This region corresponds to the removal of physiosorbed water in the interlayer region. In the second region (II), a mass loss of $5.23 \%$ and $3.63 \%$, with a sharp inflection points at 276.0 and $378.1^{\circ} \mathrm{C}$ in the derivative analysis, corresponds to the dehydroxylation process of the layers. In the third region (III), two peaks were observed, one at $509.3^{\circ} \mathrm{C}$ with a mass loss of $12.33 \%$, attributed to the quantitative decomposition of organic material, and a weak peak at $578.7^{\circ} \mathrm{C}$ with a weight loss of $5.78 \%$, corresponding to the decomposition of the residue of the immobilized organic anions [32]. 


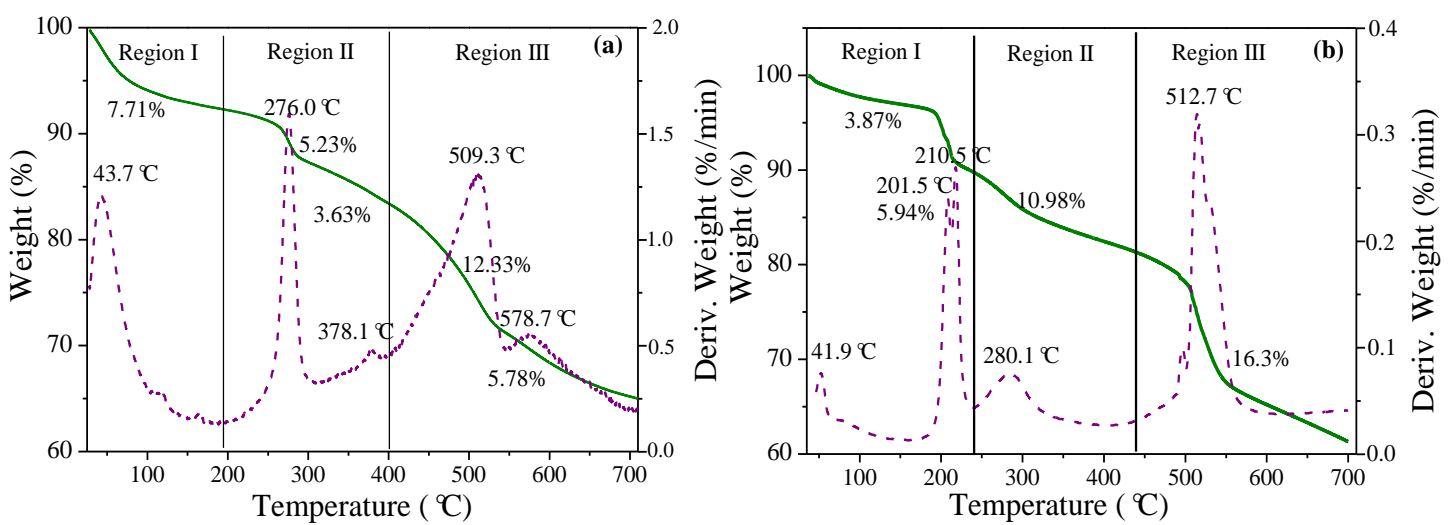

Figure 4. Thermogravimetric analysis (TG/DTA) of the hybrid compounds for (a) ZHN-CA and (b) ZHA-CA.

For ZHA-CA, the thermal decomposition revealed that the total mass loss value was $37.09 \%$ upon heating at $700{ }^{\circ} \mathrm{C}$, which was slightly higher than that of ZHN-CA. In the first region (I), a mass loss of $3.87 \%$ is associated with the removal of physiosorbed water molecules [19]. The peaks at 201.5, 210.5, and $280.1{ }^{\circ} \mathrm{C}$, in the derivative analysis, are associated with the beginning of the dehydroxylation process, as well as the decomposition of the organic species, which is evidenced with a mass loss of $16.92 \%$. The third region had a sharp peak with a mass loss of $16.30 \%$ at $512.7^{\circ} \mathrm{C}$, which can be associated with the decomposition of the immobilized organic species (CA). From the results, the hybrid material $\mathrm{ZHN}-\mathrm{CA}$ showed a thermal stability of $65.5^{\circ} \mathrm{C}$ higher than that of the ZHA-CA, since the start of the dehydroxylation process was delayed.

\subsection{FT-IR Spectroscopy}

The FT-IR spectra of the host materials ZHN and ZHA, and hybrid compounds, ZHN-CA and ZHA-CA, are shown in Figure 5a,b. For the host matrix, ZHN, a broad absorption band around $3448 \mathrm{~cm}^{-1}$ attributed to the $\mathrm{O}-\mathrm{H}$ stretching, due to the presence of hydroxyl groups of $\mathrm{ZHN}$ and physically adsorbed water, can be observed. The sharp band at $3571 \mathrm{~cm}^{-1}$ can be associated with $\mathrm{OH}$ stretching vibrations, non-H-bonded [33-35]. The band at $1638 \mathrm{~cm}^{-1}$ can be attributed to the $\mathrm{OH}$ bending vibrational mode of water molecules occupying the interlayer spacing [35,36]. The strong band located at $1378 \mathrm{~cm}^{-1}$ corresponds to the stretching vibration of free nitrate groups within the interlayer region, whereas the band located at $1022 \mathrm{~cm}^{-1}$ can be associated with the prohibited stretching mode of the nitrate group [36]. The bands at 882 and $832 \mathrm{~cm}^{-1}$ can be assigned to the $\mathrm{C}-\mathrm{O}$ vibrational mode of carbonate anions [37]. The bands around $764 \mathrm{~cm}^{-1}, 639 \mathrm{~cm}^{-1}$, and $462 \mathrm{~cm}^{-1}$ are attributed to the vibrations of $\mathrm{Zn}-\mathrm{O}$ [21]. For the host matrix ZHA, the broad band at $3440 \mathrm{~cm}^{-1}$, just like in $\mathrm{ZHN}$, can be assigned to the $\mathrm{O}-\mathrm{H}$ stretching vibration mode. The bands around 1560 and $1400 \mathrm{~cm}^{-1}$ are associated with $\mathrm{COO}^{-}$ asymmetric and symmetric vibrational modes, respectively. The difference in the $v_{\mathrm{a}}\left(\mathrm{COO}^{-}\right)$and $v_{\mathrm{s}}\left(\mathrm{COO}^{-}\right)$ $\left(\Delta v_{\mathrm{a}-\mathrm{s}}=160 \mathrm{~cm}^{-1}\right)$ stretching frequency indicates an ionic mode in the coordination of the carboxylate group to the layered structure, according to the description given by Nara et al. [38].

The bands at 1334 and $1049 \mathrm{~cm}^{-1}$ can be associated with the vibration modes of the methyl group $\left(\mathrm{CH}_{3}\right)$ due to deformation and rocking, respectively [39]. The weak band at $831 \mathrm{~cm}^{-1}$ is attributed to the $\mathrm{CO}_{3}{ }^{2-}$ scissoring vibration mode, and the bands at lower wavenumbers are assigned to the $\mathrm{Zn}-\mathrm{OH}$ vibrations. For both intercalated compounds, the bands associated with the starting anions, located in the interlayer distances (1378 and $1560-1400 \mathrm{~cm}^{-1}$ ) of the host matrices, were not evident. These changes also demonstrate the immobilization process of the caffeate anions in the interlayer region. For ZHN-CA, the broad band centered at $3440 \mathrm{~cm}^{-1}$ is associated with the $\mathrm{OH}$ vibration mode of the layers and water molecules located in the interlayer space [19], whereas, for ZHA-CA, in this region, the bands at 3431 and $3230 \mathrm{~cm}^{-1}$ are assigned to the stretching vibration mode of the $\mathrm{OH}$ group of the aromatic ring of the caffeic acid molecule $[40,41]$. These results agree with the thermal analysis, where 
the loss mass due to the water molecules was lower in ZHA-CA than for ZHN-CA in the temperature range $30{ }^{\circ} \mathrm{C}-150{ }^{\circ} \mathrm{C}$. The bands observed in the range from 1598 to $1421 \mathrm{~cm}^{-1}$ are attributed to the stretching vibration mode of the $\mathrm{C}-\mathrm{C}$ group. The bands at 1643 and $838 \mathrm{~cm}^{-1}$ are related to the $\mathrm{C}=\mathrm{O}$ group vibration mode. The band at around $1267 \mathrm{~cm}^{-1}$ corresponds to the stretching vibration mode of the $\mathrm{C}-\mathrm{OH}$ group $[41,42]$.
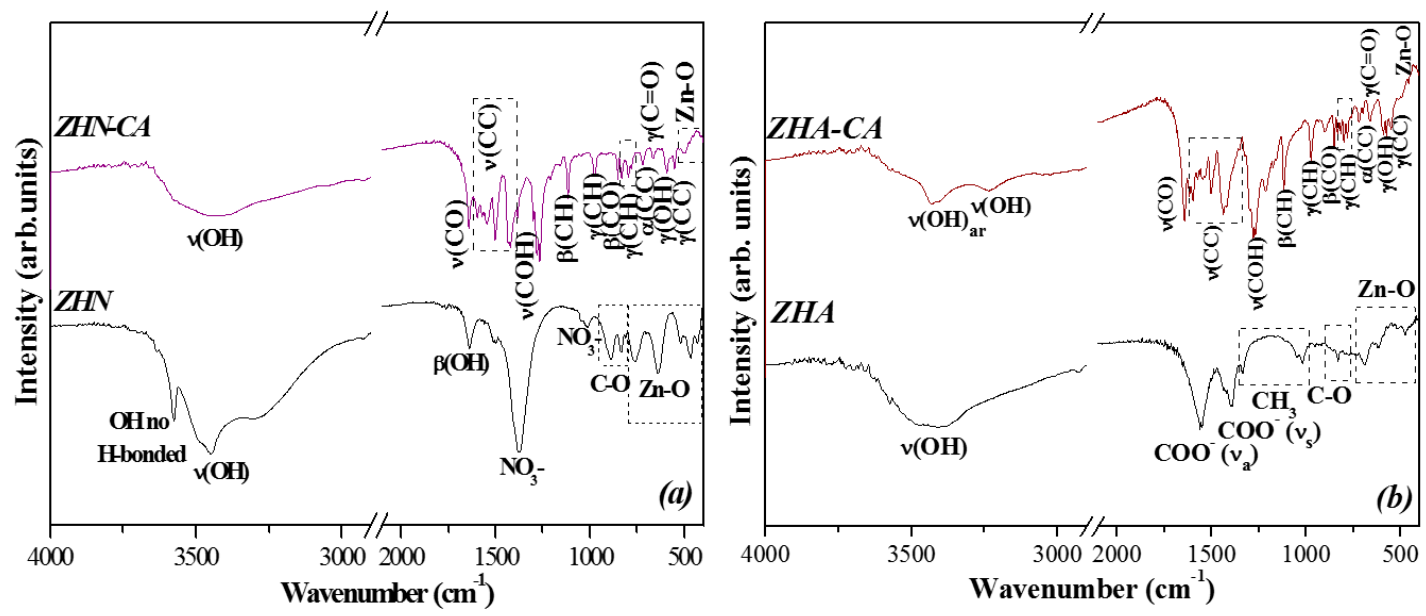

Figure 5. Fourier transform infrared spectra for: (a) ZHN and ZHN-CA, and (b) ZHA and ZHA-CA.

The bands in the range from 1116 to $796 \mathrm{~cm}^{-1}$ are associated with the different vibration modes of the $\mathrm{CH}$ group, with the higher wavenumber due to the in-plane bending and the lower wavenumber due to out-of-plane bending vibration [42]. The bands at 723 and $671 \mathrm{~cm}^{-1}$ are assigned to the aromatic ring out-of-plane bending mode of the $\mathrm{C}-\mathrm{C}$ group and in-plane bending mode of the $\mathrm{C}=\mathrm{O}$ group, respectively. The band around $592 \mathrm{~cm}^{-1}$ can be assigned to out-of-plane bending $\mathrm{O}-\mathrm{H}$ vibration, whereas the band at $551 \mathrm{~cm}^{-1}$ corresponds to the aromatic ring in-plane bending mode of the $\mathrm{C}-\mathrm{C}$ group [43]. The vibrations at lower wavenumbers can be attributed to the $\mathrm{Zn}-\mathrm{O}$ stretching vibration [36]. These results are in accordance with the XRD patterns for the immobilization process of caffeate anions for both layered inorganic systems, ZHN and ZHA [19].

\subsection{Scanning Electron Microscopy (SEM)}

The SEM images for ZHN and ZHA, as well as those for the hybrid materials, ZHN-CA and ZHA-CA, are shown in Figure 6. ZHN (Figure 6a) exhibited well-defined crystals with the characteristic plate-like morphology of layered materials. The morphology of the intercalated compound ZHN-CA (Figure $6 \mathrm{~b}$ ) showed agglomerated particles with a heterogeneous distribution. For the ZHA host matrix, a non-uniform sheet and flake-like structure were observed (Figure 6c). However, ZHA-CA exhibited a dense structure with a smoother surface and small particles on the surface (Figure $6 \mathrm{~d}$ ). These results show clear differences in the morphology between the inorganic host matrices and the hybrid materials, which can affect the general properties of the materials.

\subsection{X-Ray Photoelectron Spectroscopy (XPS)}

The high-resolution XPS spectra of the chemical states of Zn, C, and O are shown in Figure 7a,b for the inorganic host matrices and hybrid materials. For the ZHN host matrix, the $\mathrm{Zn} 2 p_{3 / 2}$ core level spectrum exhibited two contributions with binding energies at 1021.4 and $1023.1 \mathrm{eV}$. These contributions are related to the structural characteristics of the layered host matrix, where the $\mathrm{Zn}^{2+}$ atoms have tetrahedral and octahedral coordination in the $\mathrm{Zn}_{5}(\mathrm{OH})_{8}\left(\mathrm{NO}_{3}\right)_{2} \cdot 2 \mathrm{H}_{2} \mathrm{O}$ structure $[14,22]$. The binding energy values for $\mathrm{O} 1 \mathrm{~s}$ were $529.9,531.4$, and $533.1 \mathrm{eV}$, which correspond to $\mathrm{CO}_{3}{ }^{2-},-\mathrm{OH}$, and $\mathrm{NO}_{3}{ }^{-} / \mathrm{H}_{2} \mathrm{O}$, respectively. The presence of carbonate ions is due to the high affinity of the layers with compatible chemical species such as $\mathrm{CO}_{2}$ [21]. Based on the peak fitting, the intense peak corresponds 
to the contribution of $\mathrm{Zn}(\mathrm{OH})_{2}$, which forms the layers. In contrast, the peak at higher binding energy is related to the nitrate anions that act as counterions, and adsorbed water molecules occupying the interlayer spaces of the layered structure. For the $\mathrm{C} 1 \mathrm{~s}$ core-level spectrum, three contributions were detected with energies of $284.7,287.4$, and $289.5 \mathrm{eV}$, associated with $\mathrm{C}-\mathrm{H}, \mathrm{C}=\mathrm{O}$, and $\mathrm{CO}_{3}{ }^{2-}$, respectively. The lower binding energy value is assigned to adventitious carbon, which is usually found on the surface of most samples exposed to air, whereas the two higher binding energy values are associated with the presence of the carbonate ion.
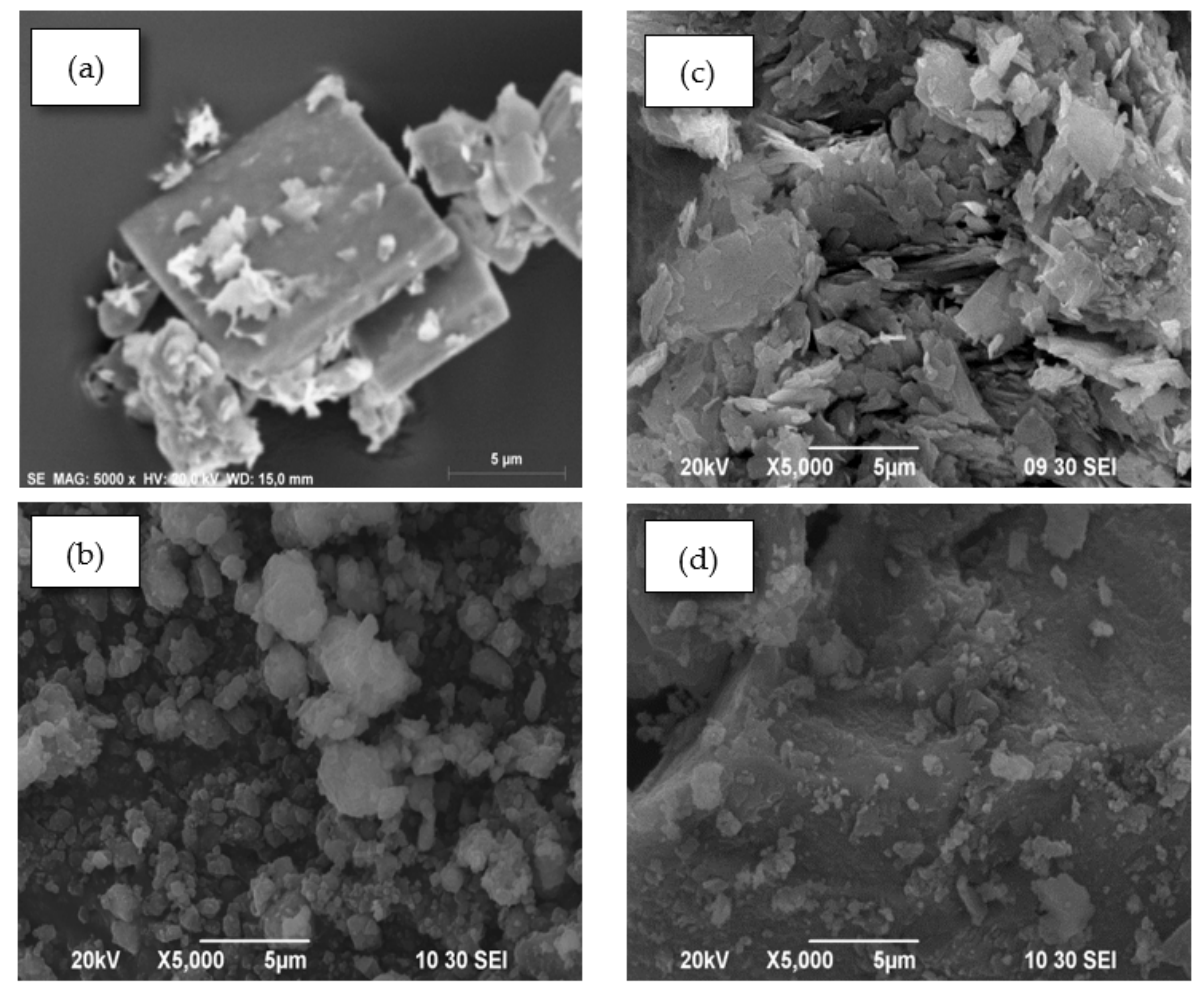

Figure 6. SEM images of (a) ZHN host matrix, (b) ZHN-CA, (c) ZHA, and (d) ZHA-CA.

For the intercalated compound $\mathrm{ZHN}-\mathrm{CA}$, the $\mathrm{C}$ 1s core-level spectrum showed four contributions after the peak fitting. The band at $284.5 \mathrm{eV}$ is assigned to $\mathrm{C}-\mathrm{H}$, due to the aromatic ring of the caffeate anion, as well as to the adventitious carbon. The chemical state of $\mathrm{C} 1 \mathrm{~s}$ at $286.0 \mathrm{eV}$ is attributed to the carboxylate group $\left(\mathrm{COO}^{-}\right)$, which participated in the covalent bonding with the $\mathrm{Zn}^{2+}$ tetrahedral units of the layers to form the hybrid compound. The band around $288.4 \mathrm{eV}$ corresponds to the phenolic group $(\mathrm{C}-\mathrm{OH})$ confirming the caffeic acid molecule, and the weak band at a higher binding energy, $290.3 \mathrm{eV}$, is assigned to the presence of the carbonate anion in the intercalation compound. The O $1 \mathrm{~s}$ core level for the hybrid compound, ZHN-CA, exhibited two bands at $531.9 \mathrm{eV}$ and $533.4 \mathrm{eV}$. The band at the lower binding energy corresponds to the $\mathrm{Zn}(\mathrm{OH})_{2}$ which forms to the layers, and the band at the higher binding energy can be associated with the carboxylate group $\left(\mathrm{COO}^{-}\right)$of the organic molecule. For the hybrid material, two chemical states for $\mathrm{Zn} 2 p_{3 / 2}$ were identified at 1022.2 and $1023.4 \mathrm{eV}$, which are related to the different chemical environments of the $\mathrm{Zn}^{2+}$ atom in the octahedral and tetrahedral units of the layered structure.

In the case of the ZHA host matrix, the $\mathrm{C}$ 1s core-level spectrum showed three bands with binding energy values at $284.8,286.2$, and $288.9 \mathrm{eV}$. The band at the lower binding energy value is assigned to the $\mathrm{C}-\mathrm{H}$ associated with the presence of the methyl group of the acetate molecule and the adventitious carbon. The band around $286.2 \mathrm{eV}$ is related to $\mathrm{C}=\mathrm{O}$ bonds, and the band at the higher binding energy value is also assigned to the presence of the carboxylate group of the acetate anion [22]. These results agree with the FT-IR analysis previously described. The O 1 s core-level spectrum exhibited three 
contributions. The band around at $530.2 \mathrm{eV}$ is assigned to the presence of carbon species such as $\mathrm{CO}_{2}$. The strong band at $531.6 \mathrm{eV}$ corresponds to the $\mathrm{Zn}(\mathrm{OH})_{2}$ forming the layers, and the band at the higher binding energy value $(532.6 \mathrm{eV})$ is related to the carboxylate group $\left(\mathrm{COO}^{-}\right)$of the acetate anions. From the $\mathrm{Zn} 2 p_{3 / 2}$ core level, two peaks were identified, one of them corresponds to $\mathrm{Zn}^{2+}$ with octahedral coordination to the hydroxyl groups at $1021.8 \mathrm{eV}$, and the other is a weak band associated with the tetrahedral coordination of the $\mathrm{Zn}^{2+}$ atom.
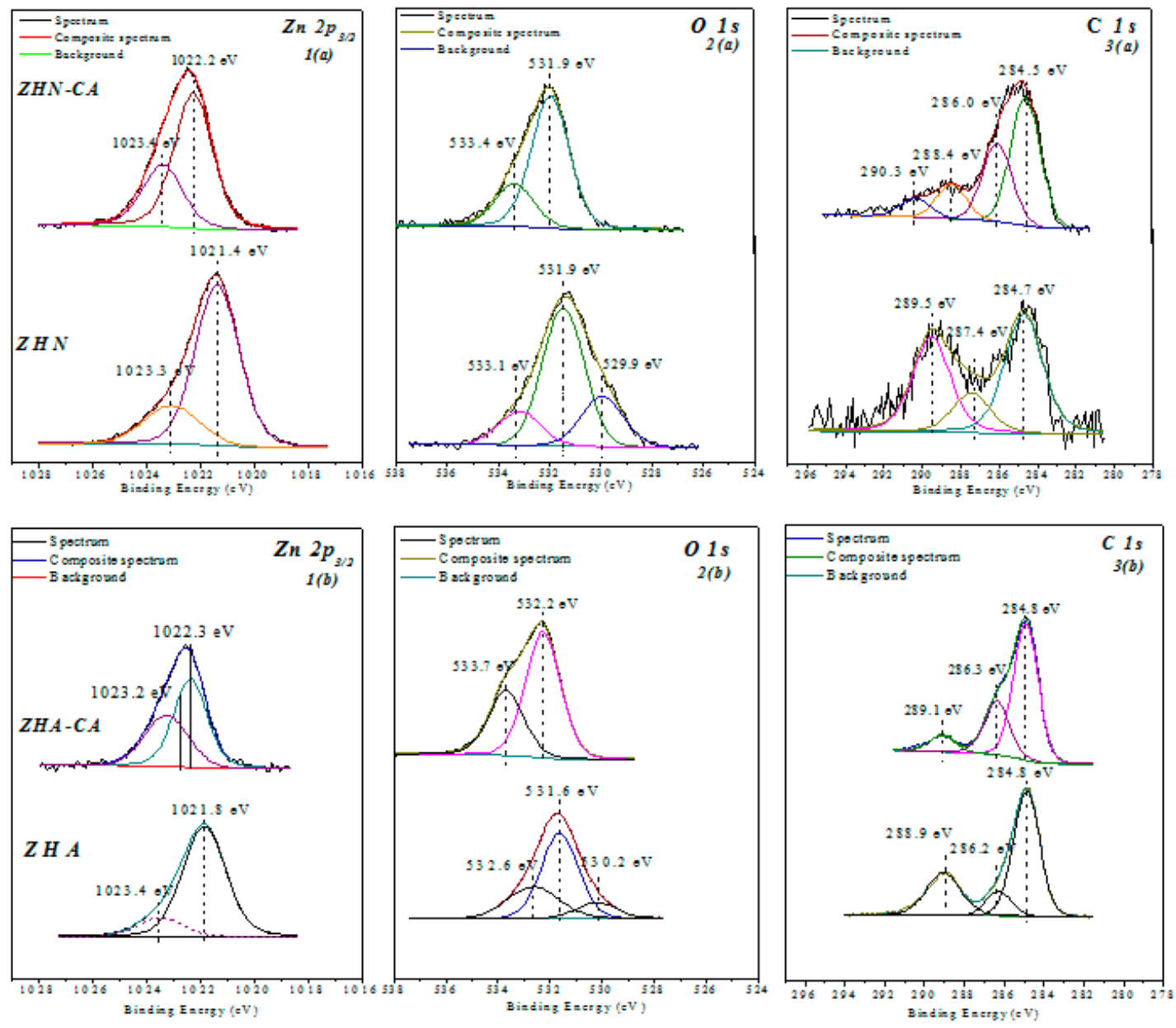

Figure 7. High-resolution XPS of chemical state (1) Zn $2 p_{3 / 2}$, (2) O 1s, and (3) C 1s for (a) ZHN and ZHN-CA, and (b) ZHA and ZHA-CA.

For the hybrid material ZHA-CA, the C 1s core-level spectrum exhibited only three contributions at 284.8, 286.3, and $289.1 \mathrm{eV}$. The component related to carbon species at higher binding energy was not found like for ZHN-CA. However, for the $\mathrm{O} 1 s$ and $\mathrm{Zn} 2 p_{3 / 2}$ core-level spectra, similar contributions were identified after the peak fitting of this hybrid material. The results of XPS are in accordance with those of XRD and FT-IR analysis, which could confirm the immobilization process of the organic molecules in both starting layered structures, since, although the starting materials were different, the hybrid compounds gave rise to a single arrangement of the caffeate anions in both layered structures. The displacement of the binding energy values for the different core levels, $\mathrm{C} 1 s, \mathrm{O} 1 \mathrm{~s}$, and $\mathrm{Zn} 2 p_{3 / 2}$, between the host matrices and the hybrid compounds, is related to the change in chemical environment after the interaction, through H-bonding, between the water molecules of the tetrahedral units of the layers and the carboxylate group of caffeate anions. For both inorganic host matrices, $\mathrm{ZHN}$ and $\mathrm{ZHA}$, the binding energy values for the tetrahedral coordinated $\mathrm{Zn}^{2+}$ ions were similar. Nevertheless, the change in the intensity of this contribution can be related to the structural variation of the layered host, since, for ZHA, the amount of water in crystallization may vary, depending on the 
synthesis method [20], thereby affecting its availability and the possibility of interaction with guest organic molecules.

\subsection{Controlled Release}

The CA release profiles of ZHN-CA and ZHA-CA in pH 7.1 buffer solution are given in Figure 8. For $\mathrm{ZHN}-\mathrm{CA}$, a faster release of $\mathrm{CA}$ was reached in comparison to the hybrid compound ZHA-CA. The CA released amount was about $\sim 80 \%$ in $300 \mathrm{~min}$ for $\mathrm{ZHN}-\mathrm{CA}$, whereas only $\sim 66 \%$ was released for ZHA-CA. These results reveal differences in the interactions between the organic anions and the layers of the two host matrices, ZHA and ZHN. As a result, there was a stronger coordination bonding between carboxylate groups of the caffeate anions with the ZHA than that with the ZHN, in concordance with the analysis of interfacial characterization made in the previous section (Section 3.2). Therefore, the release process was slower and more restricted than that for ZHN-AC. For ZHA-CA, the release behavior achieved an equilibrium after $420 \mathrm{~min}$ with $\sim 74 \%$, whereas, for ZHN-CA, 480 min were necessary with $\sim 95 \%$ release. The results indicate that the hybrid compounds have potential use as controlled release systems.

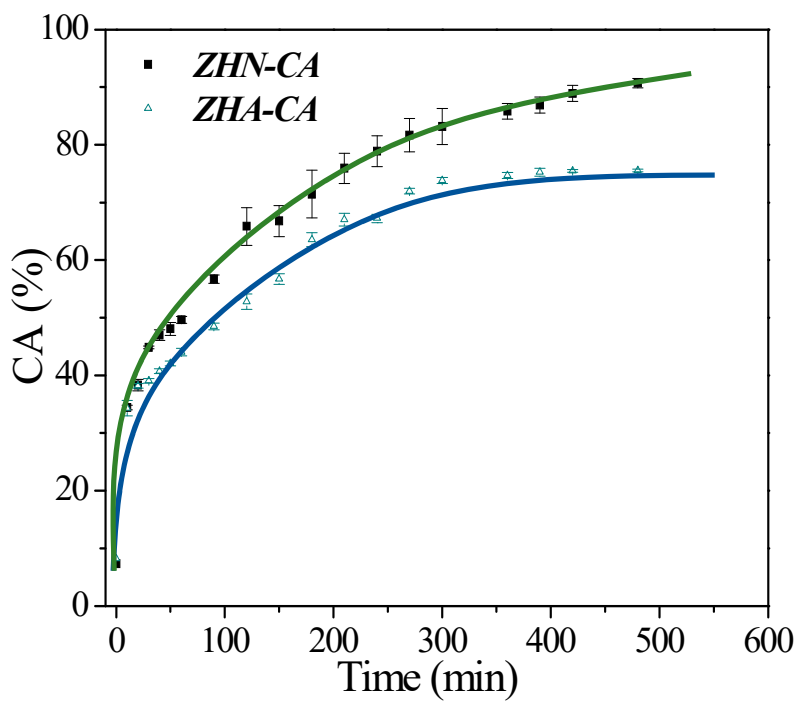

Figure 8. Release profiles for CA from ZHN-CA and ZHA-CA in buffer solutions at $\mathrm{pH}$ 7.1. Solid lines are a guide for the behavior of the releasing profile and have no physical significance. The curves correspond to the average of three experimental measurements for each point.

\subsection{Kinetic Analysis}

To explore the kinetics of the release process of caffeate anions from the hybrid compounds, four models were evaluated. The release data were fitted by the parabolic, Freundlich, Elovich, and Avrami-Erofe'ev models, and the fitted plots are displayed in Figure 9. The equations of these models and the $R^{2}$ coefficients from the fitting are presented in Table 2. It was found that the release data fitted well when using the Elovich and Avrami-Erofe'ev models for both hybrid compounds. The model provided better fitting of the data for ZHN-CA with the correlation coefficient being higher than for ZHA-CA. Based on these results, the release processes for the hybrid compounds were mainly governed by the surface diffusion [16,42], and the better release behavior for ZHN-CA can be related to the chemical composition, structural characteristics, and morphology of this hybrid compound compared to ZHA-CA. 

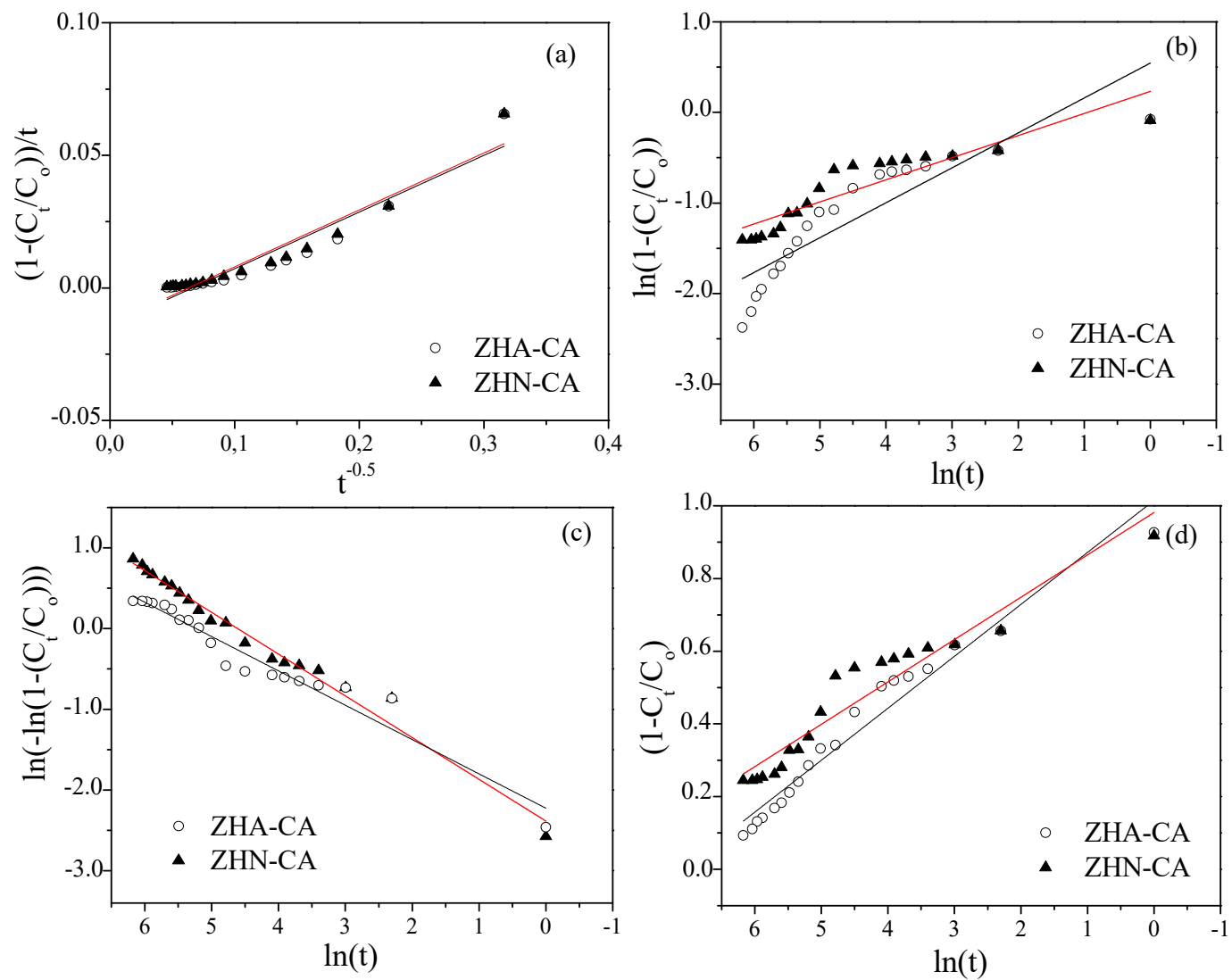

Figure 9. Plots of kinetic models to the experimental release of CA anions from ZHN-CA and ZHA-CA hybrid materials: (a) parabolic, (b) Freundlich, (c) Avrami-Erofe'ev, and (d) Elovich models.

Table 2. Equations of kinetic models for release analysis and $R^{2}$ coefficients of fitted results.

\begin{tabular}{cccc}
\hline \multirow{2}{*}{ Model } & Equation & \multicolumn{2}{c}{$\boldsymbol{R}^{\mathbf{2}}$} \\
\cline { 3 - 4 } & & ZHN-CA & ZHA-CA \\
\hline Parabolic & $\left(1-C_{\mathrm{t}} / C_{0}\right) / t=k_{\mathrm{d}}\left(t-t_{0}\right)^{-0.5}+a$ & 0.9293 & 0.9139 \\
Freundlich & $\ln \left(1-C_{\mathrm{t}} / C_{0}\right)=\ln \left(k_{\mathrm{d}}\right)+a \ln \left(\left(t-t_{0}\right)\right)$ & 0.8378 & 0.7837 \\
Elovich & $1-C_{\mathrm{t}} / C_{0}=a \ln \left(\left(t-t_{0}\right)\right)+b$ & 0.9554 & 0.9206 \\
Avrami-Erofe'ev & $\ln \left(-\ln \left(C_{\mathrm{t}} / C_{0}\right)\right)=\operatorname{nln} k_{\mathrm{d}}+\operatorname{nln}\left(t-t_{0}\right)$ & 0.9754 & 0.9494 \\
\hline
\end{tabular}

$C_{0}$ represents the amount of CA anions in ZHN and ZHA at $t=0, C_{t}$ is the amount of CA anions in ZHN and ZHA at time $t$, and $k_{\mathrm{d}}$ is the rate of release. $a, b$, and $n$ are constants. The $R^{2}$ coefficients were obtained from three replicas of the response taken for each time level by using the statistical package XLSTAT-2019 [43].

\section{Conclusions}

Caffeic acid was successfully immobilized into the ZHN and ZHA host matrices. Variations of the chemical composition of the hybrid materials were estimated from the elemental analysis, and the values of zeta potential evidenced differences in the surface charge of the starting layered host matrices, which affected the resulting layered structures of the hybrid materials.

The basal spacing of ZHN-CA was $10.20 \AA$ and, for ZHA-CA, the $d$-value was $10.37 \AA$, indicating that the caffeate anions were arranged, with a tilt angle of $70^{\circ}$, along the $z$-axis in the interlayer space of the $\mathrm{ZHN}$ and $\mathrm{ZHA}$ structures. The strong interaction between the carboxylate groups of the caffeic acid molecule and the $\mathrm{Zn}^{2+}$ of the tetrahedral units produced the substitution of the water molecules occupying the apex of the tetrahedron, giving rise to the arrangement of the CA anions in the interlayer region.

The immobilization of caffeate anions in both host matrices was confirmed by FT-IR analysis and XPS analysis, although the differences in chemical environment of the starting layered structures 
defined the superficial characteristics and morphology of the hybrid compounds. The total mass loss during the heat treatment was higher for the intercalation compound ZHN-CA (34.68\%) than for ZHA-CA (37.09\%) due to the difference in the amount of adsorbed water and the water in crystallization molecules of the host matrices. An enhancement of $65^{\circ} \mathrm{C}$ of the thermal stability was observed for $\mathrm{ZHN}-\mathrm{CA}$ due to the retardation of the dehydroxylation process. The release profiles indicated a lower release of CA for ZHA-CA, which is related to the stronger interaction between the layers and the guest anions. The Elovich and Avrami-Erofe'ev models described the release process, through a surface diffusion mechanism, for both hybrid compounds. These results indicate that $\mathrm{ZHN}-\mathrm{CA}$ and ZHA-CA have potential for use as controlled release formulations of organic molecules, with antioxidant properties.

Author Contributions: Synthesis conceptualization, O.G.; methodology, O.G., C.V.R. and M.E.B.; validation, C.V.R.; formal analysis, C.V.R. and O.G.; resources, O.G. and M.E.B.; investigation and data curation, C.V.R.; writing-original draft preparation, C.V.R.; writing—review and editing, M.E.B. and O.G.; visualization, M.E.B.; supervision, O.G. All authors have read and agree to the published version of the manuscript.

Funding: This research was funded by the Fondo de Ciencia, Tecnología, e Innovación del Sistema General de Regalías, the Fondo Nacional de Financiamiento para la Ciencia, la Tecnología y la Innovación "Francisco José de Caldas", MINCIENCIAS (COLCIENCIAS), Programa Colombia BIO, Gobernación de Boyacá through FP44842-298-2018, and MINCIENCIAS (COLCIENCIAS) as financial support of the doctoral studies of Christhy V. Ruiz through announcement 647-2015.

Acknowledgments: The authors would like to thank Enrique Rodriguez Castellón of Málaga University for the XPS analysis and scanning electron microscopy, and the characterization services of the Institute of the Science and Technology of the Polymers (ICTP/CSIC) for the thermal analysis and zeta potential measurements.

Conflicts of Interest: The authors declare no conflict of interest.

\section{References}

1. Oh, J.-M.; Biswick, T.T.; Choy, J.-H. Layered nanomaterials for green materials. J. Mater. Chem. 2009, 19, 2553. [CrossRef]

2. Rojas, R.; Linck, Y.G.; Cuffini, S.L.; Monti, G.A.; Giacomelli, C.E. Structural and physicochemical aspects of drug release from layered double hydroxides and layered hydroxide salts. Appl. Clay Sci. 2015, 109, 119-126. [CrossRef]

3. Kalali, E.N.; Wang, X. Multifunctional intercalation in layered double hydroxide: Toward multifunctional nanohybrids for epoxy resin. J. Mater. Chem. A 2016, 4, 2147-2157. [CrossRef]

4. Arízaga, G.G.C.; da Costa Gardolinski, J.E.F.; Schreiner, W.H.; Wypych, F. Intercalation of an oxalatooxoniobate complex into layered double hydroxide and layered zinc hydroxide nitrate. J. Colloid Interface Sci. 2009, 330, 352-358. [CrossRef] [PubMed]

5. Carlino, S.; Hudson, M.J. Thermal intercalation of layered double hydroxides: Capric acid into an Mg-AI LDH. J. Mater. Chem. 1995, 5, 1433. [CrossRef]

6. Gasser, M. Inorganic layered double hydroxides as ascorbic acid (vitamin C) delivery system-Intercalation and their controlled release properties. Colloids Surf. B Biointerfaces 2009, 73, 103-109. [CrossRef] [PubMed]

7. Saifullah, B.; Hussein, M.Z.B.; Bullo, S.; Hussein, M.Z. Inorganic nanolayers: Structure, preparation, and biomedical applications. Int. J. Nanomed. 2015, 10, 5609-5633.

8. Barahuie, F.; Hussein, M.Z.; Fakurazi, S.; Zainal, Z. Development of drug delivery systems based on layered hydroxides for nanomedicine. Int. J. Mol. Sci. 2014, 15, 7750-7786. [CrossRef]

9. Bull, R.M.R.; Markland, C.; Williams, G.R.; O’Hare, D. Hydroxy double salts as versatile storage and delivery matrices. J. Mater. Chem. 2011, 21, 1822-1828. [CrossRef]

10. Moezzi, A.; Cortie, M.B.; Shimmon, R.; McDonagh, A.M. On the Reactivity of Zinc Hydroxide Acetate Dihydrate in Ethanol. Eur. J. Inorg. Chem. 2013, 2013, 5133-5137. [CrossRef]

11. Arizaga, G.G.C.; Satyanarayana, K.; Wypych, F. Layered hydroxide salts: Synthesis, properties and potential applications. Solid State Ion. 2007, 178, 1143-1162. [CrossRef]

12. Latip, A.F.A.; Hussein, M.Z.; Stanslas, J.; Wong, C.C.; Adnan, R.; Latip, A.A.; Latip, A.F.A. Release behavior and toxicity profiles towards A549 cell lines of ciprofloxacin from its layered zinc hydroxide intercalation compound. Chem. Cent. J. 2013, 7, 119. [CrossRef] 
13. Hussein, S.H.; al Ali, H.; Al-Qubaisi, M.; el Zowalaty, M.; Hussein, M.Z.; Ismail, M. Antimicrobial activity of hippurate nanocomposite and its cytotoxicity effect in combination with cytarabine against HL-6. J. Nanomater. 2013, 2013, 843647. [CrossRef]

14. Silion, M.; Hritcu, D.; Lisa, G.; Popa, M.I. New hybrid materials based on layered double hydroxides and antioxidant compounds. Preparation, characterization and release kinetic studies. J. Porous Mater. 2012, 19, 267. [CrossRef]

15. Baykal, A.; Amir, M.; Günerb, S.; Sözeri, H. Preparation and characterization of SPION functionalized via caffeic acid. J. Magn. Magn. Mater. 2015, 395, 199-204. [CrossRef]

16. Swisłocka, R. Spectroscopic (FT-IR, FT-Raman, UV absorption, ${ }^{1} \mathrm{H}$ and ${ }^{13} \mathrm{C}$ NMR) and theoretical (in B3LYP/6-311++G** level) studies on alkali metal salts of caffeic acid. Spectrochim. Acta Part A Mol. Biomol. Spectrosc. 2013, 100, 21-30. [CrossRef]

17. Gao, T.; Ci, Y.; Jian, H.; An, C. FTIR investigation of the interaction of tumor cells treated with caffeic acid and chlorogenic acid. Vib. Spectrosc. 2000, 24, 225. [CrossRef]

18. Wei, Y.; Gao, Y.; Zhang, K.; Ito, Y. Isolation of Caffeic Acid from Eupatorium Adenophorum Spreng by High-Speed Countercurrent Chromatography and Synthesis of Caffeic Acid-Intercalated Layered Double Hydroxide. J. Liq. Chromatogr. Relat. Technol. 2010, 33, 837-845. [CrossRef]

19. Biswick, T.; Park, D.-H.; Choy, J.-H. Enhancing the UV A1 screening ability of caffeic acid by encapsulation in layered basic zinc hydroxide matrix. J. Phys. Chem. Solids 2012, 73, 1510-1513. [CrossRef]

20. Moezzi, A.; McDonagh, A.; Dowd, M. Cortie, Zinc hydroxyacetate and its transformation to nanocrystalline zinc oxide. Inorg. Chem. 2013, 52, 95. [CrossRef]

21. Ruiz, C.V.; Rodriguez-Castellón, E.; Giraldo, O. Structural analysis and conduction mechanism in polycrystalline zinc hydroxide nitrate. Inorg. Chem. 2018, 57, 9067. [CrossRef]

22. Moulder, J.F.; Sobol, W.F.; Bomben, K.D. Handbook of X-ray Photoelectron Spectroscopy; Physical Electronic Division, Perkin-Elmer Corporation: Eden Praire, MN, USA, 1995.

23. Multipak Software; Version 9.6.0.15.; Physical Electronics: Chanhassen, MN, USA, 2015.

24. Interactive Crystal \& Molecular Modelling; Version 9.2.6.; CrystalMaker Software: Begbroke, UK, 2015.

25. Xu, Z.P.; Jin, Y.; Liu, S.; Hao, Z.P.; Lu, G.Q. Surface charging of layered double hydroxides during dynamic interactions of anions at the interfaces. J. Colloid Interface Sci. 2008, 326, 522-529. [CrossRef]

26. Xu, Z.P.; Stevenson, G.; Lu, C.Q.; Lu, G.Q. Dispersion and size control of layered double hydroxide nanoparticles in aqueous solutions. J. Phys. Chem. B 2006, 110, 16923-16929. [CrossRef]

27. Tran, H.N.; Lin, C.C.; Woo, S.H.; Chao, H.P. Efficient removal of copper and lead by Mg/Al layered double hydroxides intercalated with organic acid anions: Adsorption kinetics, isotherms, and thermodynamics. Appl. Clay Sci. 2018, 154, 17-27. [CrossRef]

28. Zhao, J. Synthesis of functionalized MgAl-layered double hydroxides via modified mussel inspired chemistry and their application in organic dye adsorption. J. Colloid Interface Sci. 2017, 505, 168-177. [CrossRef]

29. Moaty, S.A. Synthesis and characterization of LDH-type anionic nanomaterials for effective removal of doxycycline from aqueous media. Water Environ. J. 2019, 1-34. [CrossRef]

30. Joseph, E.; Singhvi, G. Multifunctional nanocrystals for cancer therapy: A potential nanocarrier. Nanomater. Drug Deliv. Ther. 2019, 91-116. [CrossRef]

31. Poul, L.; Jouini, N.; Fiévet, F. Layered Hydroxide Metal Acetates (Metal=Zinc, Cobalt, and Nickel): Elaboration via Hydrolysis in Polyol Medium and Comparative Study. Chem. Mater. 2000, 12, 3123-3132. [CrossRef]

32. Xiao, Z.; Guo, M.; Guo, R. Thermal decomposition mechanism and kinetics of ursolic acid and caffeic acid. Chem. Ind. For. Prod. 2014, 34, 33-39.

33. Biwick, T.; Jones, W.; Pacuła, A.; Serwicka, E.; Podobinski, J. The role of anhydrous zinc nitrate in the thermal decomposition of the zinc hydroxy nitrates $\mathrm{Zn}_{5}(\mathrm{OH})_{8}\left(\mathrm{NO}_{3}\right)_{2} \cdot 2 \mathrm{H}_{2} \mathrm{O}$ and $\mathrm{ZnOHNO}_{3} \cdot \mathrm{H}_{2} \mathrm{O}$. J. Solid State Chem. 2007, 180, 1171-1179. [CrossRef]

34. Tavares, S.R.; Vaiss, V.S.; Wypych, F.; Leitão, A.A. Theoretical study of the anion exchange properties and the thermal decomposition of $\mathrm{Zn}_{5}(\mathrm{OH})_{8}\left(\mathrm{NO}_{3}\right)_{2} \cdot 2 \mathrm{H}_{2} \mathrm{O}$ and $\mathrm{Zn}_{5}(\mathrm{OH})_{8}\left(\mathrm{NO}_{3}\right)_{2} \cdot 2 \mathrm{NH}_{3}$. Appl. Clay Sci. 2015, 114, 103. [CrossRef]

35. Thomas, N.; Rajamathi, M. Near 100\% selectivity in anion exchange reactions of layered zinc hydroxy nitrate. J. Colloid Interface Sci. 2011, 362, 493-496. [CrossRef]

36. Stählin, W.; Oswald, H.R. The infrared spectrum and thermal analysis of zinc hydroxide nitrate. J. Solid State Chem. 1971, 3, 252-255. [CrossRef] 
37. Nakamoto, K. Complex of sulfate, carbonate and related ligands. In Infrared and Raman Spectra of Inorganic and Coordination Compounds, 5th ed.; John Wiley \& Sons, Inc.: New York, NY, USA, 2008; pp. 80-88.

38. Nara, M.; Torii, H.; Tasumi, M. Correlation between the vibrational frequencies of the carboxylate group and the types of its coordination to a metal ion: An ab initio molecular orbital study. J. Phys. Chem. 1996, 100, 19812. [CrossRef]

39. Song, R.Q.; Xu, A.W.; Deng, B.; Li, Q.; Chen, G.Y. From layered basic zinc acetate nanobelts to hierarchical zinc oxide nanostructures and porous zinc oxide nanobelts. Adv. Funct. Mater. 2007, 17, 296. [CrossRef]

40. Kumar, N.; Pruthi, V.; Goel, N. Estructural, thermal and quantum chemical studies of p-coumaric and caffeic acids. J. Mol. Struct. 2015, 1085, 242. [CrossRef]

41. Selma, S.D.; Chong, R.; Patel, R.; Williams, G.R. Intercalation and controlled release of bioactive ions using a hydroxy double salt. Ind. Eng. Chem. Res. 2012, 51, 2913.

42. Liu, J.; Zhang, X.; Zhang, Y. Preparation and Release Behavior of Chlorpyrifos Adsolubilized into Layered Zinc Hydroxide Nitrate Intercalated with Dodecylbenzenesulfonate. ACS Appl. Mater. Interfaces 2015, 7, 11180-11188. [CrossRef]

43. Addinsoft. XLSTAT Statistical and Data Analysis Solution; Addinsoft: Paris, France, 2019; Available online: https://www.xlstat.com (accessed on 10 December 2019).

(C) 2020 by the authors. Licensee MDPI, Basel, Switzerland. This article is an open access article distributed under the terms and conditions of the Creative Commons Attribution (CC BY) license (http://creativecommons.org/licenses/by/4.0/). 